\title{
Motion - Laparoscopic Nissen fundoplication is more cost effective than oral PPI administration: Arguments against the motion
}

\author{
Amnon Sonnenberg MD MSc
}

\begin{abstract}
A Sonnenberg. Motion - Laparoscopic Nissen fundoplication is more cost effective than oral PPI administration: Arguments against the motion. Can J Gastroenterol 2002;16(9):627-631.
\end{abstract}

Discussion of the cost effectiveness of medical and surgical treatments of gastroesophageal reflux disease (GERD) is plagued by a number of logical fallacies. Several of these defects in reasoning are reviewed. For example, it is inappropriate to compare the costs of therapies unless they are equally effective. The relative cost effectiveness of various treatment options is difficult to determine because monetary expenditures and gains in health status cannot easily be measured in commensurate units. Not everything can be translated into incremental cost effectiveness ratios. Two decision analyses from European investigators seemed to show that Nissen fundoplication was more cost effective than long term acid-suppression therapy, but they failed to consider the costs of surgical complications and failures. The most comprehensive decision analysis, employing a Markov chain model, found that the two treatment options were roughly equivalent, at least during the first seven years of follow-up. Decision analyses often do not reflect actual practice patterns and cannot provide solutions to problems that cannot be solved by appropriate medical reasoning. Moreover, results that are reported by specialized surgical centres probably cannot be duplicated by less experienced surgeons. The increasing incidence of esophageal adenocarcinoma has been erroneously attributed to the use of potent acid-suppressant medications, but the actual cause has been shown to be the decreased prevalence of Helicobacter pylori. There are no significant differences in the incidence of this tumour after medical or surgical therapy of GERD. It is unlikely, however, that arguments will convince proponents of one treatment or another to change their opinions.

Key Words: Gastroesophageal reflux disease; Helicobacter pylori; Nissen fundoplication; Proton pump inhibitors

\section{Proposition - La fundoplication laparoscopique de Nissen offre un meilleur rapport coût-efficacité que les IPP oraux : Arguments invalidants cette proposition}

RÉSUMÉ : La discussion quant au rapport coût-efficacité des traitements médicaux et chirurgicaux dans le reflux gastro-œsophagien (RGO) se heurte à un certain nombre d'idées fausses. Plusieurs de ces raisonnements fallacieux sont passés en revue ici. Par exemple, est-il approprié de comparer les coûts des traitements s'ils ne sont pas d'une égale efficacité? Le rapport coût-efficacité relatif de diverses options thérapeutiques est difficile à déterminer, puisqu'on arrive mal à mesurer en unités les dépenses et les gains monétaires associés à la santé. En effet, tout ne se traduit pas en

suite à la page suivante

This article was originally presented at a symposium entitled, "Controversies in Gastroenterology", sponsored by Axcan Pharma, Toronto, Ontario, April 8-10, 2002

Department of Veterans Affairs Medical Center 111F, 1501 San Pedro Drive SE, Albuquerque, New Mexico, USA

Correspondence and reprints: Dr Amnon Sonnenberg, Department of Veterans Affairs Medical Center 111F, 1501 San Pedro Drive SE,

Albuquerque, New Mexico 87108, USA. Telephone 505-265-1711 ext 4513, fax 505-256-5751, e-mail sonnbrg@unm.edu 
chiffres. Lors de deux analyses décisionnelles, des investigateurs européens ont semblé montré que la fundoplication de Nissen s'accompagnait d'un meilleur rapport coût-efficacité que le traitement par suppression acide à long terme, or, ces chercheurs n'ont pas tenu compte du coût des complications et des échecs de la chirurgie.

L'analyse décisionnelle la plus globale, basée sur un modèle de Markov, a permis d'établir que les deux options thérapeutiques étaient grosso modo équivalentes au moins durant les sept premières années de suivi. Or, souvent, ces analyses décisionnelles ne reflètent pas les modes de pratique réels et ne peuvent donc pas représenter des solutions à des problèmes impossibles à régler par des raisonnements médicaux appropriés. De plus, les résultats dont ont fait état les centres chirurgicaux spécialisés ne peuvent probablement pas être reproduits par des chirurgiens de moindre expérience. L'incidence croissante des adénocarcinomes de l'œsophage a, à tort, été attribuée à l'utilisation des puissants suppresseurs de l'acidité, alors que sa cause réelle a été liée à la baisse de la prévalence de Helicobacter pylori. On ne note aucune différence significative quant à l'incidence de cette tumeur après un traitement médical ou chirurgical du RGO. Il est donc improbable que des arguments arrivent à convaincre les tenants de l'un ou l'autre des traitements de changer d'opinion.
M any of the arguments that are raised in favour of Nissen fundoplication for gastroesophageal reflux disease (GERD) fall into broad categories of common logical fallacies (1).

\section{FALLACY OF IRRELEVANT THESIS}

It has been argued that fundoplication should be employed as a primary treatment for GERD because it is cheaper than chronic medical therapy. This type of argument addresses an issue that is not in dispute, and is an example of the 'fallacy of irrelevant thesis'. The primary goal of any medical intervention is success rather than cost savings. Costs become relevant only if assessed in conjunction with medical effectiveness.

When comparing two competing management options, four conclusions are possible, depending on the effectiveness and the cost of treatments. The decision against one option is easy if it is more expensive and less effective than an alternative. The decision is also easy if one option is cheaper and better than the other option. On the other hand, it is difficult to evaluate a treatment that is medically superior but more expensive, or one that is medically inferior but less expensive. Ideally, cost effectiveness ratios could be calculated that would adequately compare such options (2,3).

\section{COMPARISON BY COST EFFECTIVENESS}

Gains in patient health are achieved by investments in time and labour by medical personnel, as well as the use of health care facilities, medications, medical procedures and surgical interventions. The gains can be realized in terms of improved body image, relief of symptoms, better overall health, prevention of future disease and extended lifespan. The key difficulty in determining cost effectiveness is that it is difficult to quantify health care investments and health gains in commensurable units.

Monetary costs represent a well-established and generally accepted means of measuring health care expenditures. Most medical outcomes can be expressed by the number of saved life-years, which can be adjusted for the quality of life. A cost effectiveness analysis evaluates interventions in terms of the ratio of costs to quality-adjusted life-years (QALYs), that is, the average cost effectiveness ratio (ACER). The incremental cost effectiveness ratio (ICER) involves a comparison of a more effective medical option with a less effective alternative option. The ICER is calculated by dividing the difference in costs by the corresponding difference in effectiveness between the two options.

It is generally recommended that global costs be considered, instead of only those that are directly relevant to the patient alone or to the health care payer alone. Otherwise, the outcome of the analysis might be distorted by cost shifting. For example, the patient might favour expensive interventions and disregard the fact that their costs must be borne by the community in general. Hospital administrators, on the other hand, might not be particularly interested in the actual resolution of the disease process, and favour early discharge from hospital, even though such a policy might result in, for example, higher outpatient drug costs. From the financial perspective of the health insurer, the death of a severely disabled patient might actually represent the most favourable outcome.

\section{FALLACY OF COMPOSITION OR DIVISION}

Three studies have employed medical decision analysis to compare the cost effectiveness of fundoplication with that of maintenance antisecretory therapy for GERD (4-6). Van den Boom et al (4) found that, using the Dutch health care cost structure, open Nissen fundoplication was cheaper than maintenance therapy with omeprazole after 3.8 years, and the cost of laparoscopic fundoplication was less than that of omeprazole after only 1.4 years. In a study from Finland, Viljakka et al (5), using a Markov chain model, determined that fundoplication was less expensive than life-long therapy with either proton pump inhibitors (PPIs) or ranitidine $300 \mathrm{mg} /$ day.

Both of the European studies $(4,5)$ committed the 'fallacy of composition or division'. What is true of the part is not necessarily true of the whole. In other words, by focusing only on the success rate of fundoplication in healing $90 \%$ of heartburn, the investigators failed to make allowances in their models for surgical complications that reduce postoperative health-related quality of life (HRQL) (7-11). In fact, complications occur after $3 \%$ to $5 \%$ of Nissen fundoplications, and include wound infections, pneumonia, systemic septicemia, pulmonary embolism and even death. Surgical therapy fails in approximately $10 \%$ of cases, due to transdiaphragmatic herniation, disruption of 
the fundoplication, slipped or misplaced fundoplication, too tight or too loose a wrap, and twisted fundoplication. These untoward effects lead to re-operation in $4 \%$ to $6 \%$ of all patients. Finally, $10 \%$ to $20 \%$ of patients experience persistent heartburn or develop new symptoms, such as dysphagia, nausea or bloating.

The most comprehensive decision analysis of long term medical and surgical treatments for GERD was published by Heudebert et al (6). Again, a Markov chain model was used to evaluate various treatment options in a hypothetical cohort of middle-aged men with moderate to severe reflux esophagitis. Over a five-year time period, laparoscopic Nissen fundoplication generated 4.334 QALYs compared with 4.332 QALYs associated with omeprazole maintenance therapy. Because of this small difference (only $18 \mathrm{~h}$ ) between the two options, the incremental cost effectiveness ratio reached almost astronomical values. Thus, the added benefit of surgery over medical therapy was achieved at the expense of US $\$ 1$ to US $\$ 2$ million per QALY. As had been found by other investigators $(4,5)$, the ICER fell as the length of time after surgery increased and the initial expense of surgery was redeemed. Sensitivity analysis revealed that the choice between medical and surgical therapy depended on the cost of initial surgery and the duration of follow-up. If the cost of surgery were less than US $\$ 7,000$ and follow-up were extended to longer than seven years, then laparoscopic Nissen fundoplication became the preferred strategy. The model employed in this study accounts for changes in HRQL after treatment but does not fully adjust for the occurrence of poor surgical outcomes. The model is complicated and difficult to understand fully from the published article; many of the statements that the authors made have to be taken at face value.

\section{FALLACY OF MEDICAL DECISION ANALYSIS}

It is a misconception that medical decision analysis and health economics analysis can provide unequivocal and irrefutable solutions to problems that cannot be resolved by reflection on the medical issues alone. In these types of analyses, the inclusion of a large number of poorly defined costs, as defined from a societal perspective, can obscure the effect of a specific medical intervention. Expected overall costs are calculated by multiplying the costs associated with a given outcome and the probability of its occurrence. If the costs of specific outcomes are large, then small errors in the estimates of their probability lead to large errors in the overall expected costs.

Theoretical models tend to underestimate the true cost of a medical intervention because they are built on the assumption of rational medical practice. They fail to consider errors in judgment and performance or the impact of the practice of defensive medicine. Complex models that provide a detailed description of the disease process often become more confusing than the medical reality that they were meant to illustrate. The black box of complex medicine is thus replaced by the black box of poorly understood economics. Physicians should not, therefore, expect economists to come up with a clear answer to a problem for which no medical solution has yet been found.

There are many pitfalls and limitations to economic analyses. Not all of medicine can be reduced to ACERs and ICERs, and it is not always possible to express medical gains in terms of QALYs. For example, economic analyses are not well equipped to measure the medical benefits associated with negative test results, which provide some degree of reassurance to patients. The costs of most medical interventions vary widely among health care providers, are proprietary secrets and are not well publicized, except for the Medicare expenditures of the Health Care Finance Administration (USA). It is, therefore, frequently impossible to determine the total cost to society of a given disease.

\section{FALLACY OF SPECIAL PLEADING}

Surgeons tend to disregard the impact of poor surgical outcomes, and refer instead to the good results obtained in large series of patients by centres of excellence (12). In so doing, they commit the 'fallacy of special pleading'. In other words, they apply double standards - one for themselves (because they are special) and another stricter one for everyone else. Surgical complications and failures are said to occur only to other (bad) surgeons. In a survey of Swiss hospitals, Koelz (13) analyzed the frequency of fundoplication per hospital and year. In Switzerland, one or a few surgeons are affiliated with each individual hospital, and most surgeons practice in only one hospital. In over $90 \%$ of all surveyed hospitals, no more than two fundoplications were performed per year. In only $4 \%$ of hospitals were eight to 10 fundoplications undertaken annually, and none of the hospitals accumulated more than 10 of these procedures per year. It has previously been shown that the postsurgical complications are more frequently encountered by inexperienced surgeons.

\section{FALLACY OF LINEAR TIME}

From a surgical perspective, it has been argued that even if the costs of surgical management were to double because of surgical failures, the cost of continued maintenance therapy would surpass the cost of surgery by seven to 10 years (14). The 'fallacy of linear time' assigns equal relevance to the past, present and future. In reality, the past is soon forgotten, the presence is highly relevant and the future will change everything. Within seven years, the fundoplication wrap may become loose, the patient may win the lottery and be able to afford the most expensive therapy possible and medicine may have found a cure for GERD. As any owner of a personal computer can attest, the laws of thermodynamics, as well as technological and scientific progress, render most acquisitions, even the most advanced and precious, worthless after 10 to 15 years.

\section{FALLACY OF APPEAL TO IGNORANCE}

Because there has been no obvious development or progression of Barrett's esophagus after fundoplication, it has been 
claimed that this procedure is protective (14). Such a claim uses the inability to disprove an argument as proof of the argument's correctness, and thus represents a typical 'fallacy of appeal to ignorance'. In fact, one would be hard pressed as a clinician to name a single patient in whom progression from non-erosive GERD to erosive esophagitis and Barrett's esophagus actually occurred, regardless of the presence or absence of treatment (15). In the majority of patients, the severity of mucosal lesions remains constant, within a narrow range of one or two GERD grades, even over very long time periods. It appears that the 'what you see is what you get' rule applies. Without continuous therapy, the amount of mucosal damage seen at the first endoscopy remains largely unchanged. Although erosions, ulcers, strictures and Barrett's metaplasia are acquired rather than congenital lesions in patients with GERD, the transition between different stages must occur quite rapidly. In most cases, the disease reaches peak severity early in its course.

\section{FALLACY OF CAUSE}

During the past three decades, the incidence of esophageal adenocarcinoma (EAC) has increased in most Western countries (15). This increase coincided with the introduction of antisecretory medications, such as histamine receptor blockers $\left(\mathrm{H}_{2} \mathrm{RA}\right)$ and PPIs, and it has been speculated that their use has been responsible for the development of cancer. Inhibition of gastric secretion would result in exposure of the esophagus to bile acids that are undiluted and not precipitated by acid. There is experimental evidence that bile salts can induce esophagitis and cancer in the esophagus (16). Therefore, only fundoplication would be truly able to prevent acid reflux without simultaneously promoting the development of EAC.

The association between the introduction of potent antisecretory medication and the worldwide increase in reflux disease, however, appears to be purely coincidental. Attributing causality between two parallel trends represents a typical ecological bias or 'fallacy of cause'. Events are assumed to be causally connected when, in fact, no such relationship can be established. The rise in the occurrence of GERD and EAC in Western countries is more closely associated with the decreased prevalence of Helicobacter pylori infection (17). Chronic gastritis in the body of the stomach leads to a decrease in acid secretion and a marked reduction in the risk of reflex esophagitis (18). The improvement in hygiene among Western populations and the decline in $\mathrm{H}$ pylori-induced corpus gastritis have resulted in higher levels of acid secretion, which in turn has increased the overall susceptibility for acid-related disorders, such as GERD and EAC.

The seemingly reduced incidence of esophageal cancer after fundoplication has been used as an argument for performing this surgery. Bammer et al (14) accumulated data from several clinical studies to calculate the average frequency of adenocarcinoma after prolonged antisecretory therapy or fundoplication. But their compilation was incomplete, in that they ignored several large studies. On the other hand, they over-represented data that had been repeatedly published. The authors identified 14 cases of EAC during 2026 patient-years of antisecretory medication and 14 cases of EAC during 4122 patient-years of follow-up after fundoplication. The cancer rate after surgery was one per 294 patient-years, compared with one per 145 patientyears with medication. The $95 \%$ CIs for the estimates of cancer rates were quite large, however, and overlapped with each other. Specifically, the $95 \%$ CIs ranged from 1 per 539 to 1 per 175 and 1 per 265 to 1 per 86, respectively. Our own large study of 34,578 medically treated GERD patients and 1147 fundoplication patients also demonstrated no significant difference in the occurrence of EAC (10).

There are additional arguments that refute the claim that fundoplication is effective in preventing the development of EAC. A reasonable estimate is that EAC develops in patients with Barrett's esophagus at a rate of one per 100 patient-years. If one assumes that each patient harbours his or her Barrett's mucosa for an average of 10 years, then the cumulative rate of EAC is one per 1000 patients. It is very doubtful that fundoplication, with all of its associated costs and complications, could be justified for 1000 patients to prevent cancer in a single patient. It has been shown that even endoscopic screening, which is far less risky and costly than fundoplication, is difficult to justify for the prevention of such a rare disease as acid-related EAC (19).

\section{THE HERMENEUTIC PARADOX}

Hermeneutics is a branch of philosophy that deals with the theories about the understanding and interpretation of information (20). A well-known paradox of hermeneutics states that what is to be understood must already be known. Phrased in such a succinct fashion, the statement appears to be self-contradictory. On one hand, people are obviously capable of learning and acquiring new knowledge. Without this ability, there would be no personal or cultural advancement. The rapid increase of scientific knowledge seems to disprove the hermeneutic paradox. On the other hand, anyone who is engaged in political, philosophical or scientific discussion can attest to the difficulties involved with convincing someone else of the veracity of one's argument. Most of the time, people are unable to accept and appreciate ideas that are beyond their own level of understanding. Even scientific exchanges often comprise statements thrown across a wide chasm, and neither persuasion nor force of evidence seem capable of swaying many proponents on either side of the argument.

Thomas S Kuhn has argued that the majority of scientists fail to adopt new concepts that are alien to the established 'paradigm' of science in which they were trained (21). Science does not evolve by changing the beliefs of established scientists, but through their replacement by a new generation of scientists who are trained according to a new paradigm. Usually, controversies are not resolved, but rather become irrelevant with the passage of time. It is similarly predicted that the current controversy about the most appropriate management of GERD will not be resolved by 
any combination of arguments, economic data or decision analyses, but only rendered irrelevant by the silent barrage of time.

\section{REFERENCES}

1. Engel SM. With Good Reason. An Introduction to Informal Fallacies, 2nd edn. New York: St Martin's Press, 1982.

2. Gold MR, Siegel JE, Russel LB, Weinstein MC, eds. Cost-Effectiveness in Health and Medicine. New York: Oxford University Press, 1996.

3. Drummond MF, O'Brien B, Stoddard GL, Torrance GW. Methods for the Economic Evaluation of Health Care Programmes, 2nd edn. New York: Oxford University Press, 1997.

4. Van den Boom G, Go PMMYH, Hameeteman W, Dallemagne B, Ament AJHA. Cost effectiveness of medical versus surgical treatment in patients with severe or refractory gastroesophageal reflux disease in the Netherlands. Scand J Gastroenterol 1996;31:1-9.

5. Viljakka M, Nevalainen J, Isolauri J. Lifetime costs of surgical versus medical treatment of severe gastro-oesophageal reflux disease in Finland. Scand J Gastroenterol 1997;32:766-72.

6. Heudebert GR, Marks R, Wilcox CM, Centor RM. Choice of long-term strategy for the management of patients with severe esophagitis: a cost-utility analysis. Gastroenterology 1997;112:1078-86.

7. Hunter JG, Smith CD, Branum GD, et al. Laparoscopic fundoplication failures: patterns of failure and response to fundoplication revision. Ann Surg 1999;230:595-604.

8. Rantanen T, Halme TV, Luostarinen ME, Karhumäki LM, Könönen EO, Isolauri JO. The long term results of open antireflux surgery in a community-based health care center. Am J Gastroenterol 1999;94:1777-81.

9. Luostarinen ME, Isolauri JO. Surgical experience improves the long- term results of Nissen fundoplication. Scand J Gastroenterol 1999;34:117-20.

10. El-Serag HB, Sonnenberg A. Outcome of erosive reflux esophagitis after Nissen fundoplication. Am J Gastroenterol 1999;94:1771-6.

11. Bais JE, Bartelsman JFWM, Bonjer HJ, et al. Laparoscopic or conventional Nissen fundoplication for gastro-oesophageal reflux disease: randomised clinical trial. The Netherlands Antireflux Surgery Study Group. Lancet 2000;355:170-4.

12. Bammer T, Hinder RA, Klaus A, Klingler PJ. Five- to eight-year outcome of the first laparoscopic Nissen fundoplications. J Gastrointest Surg 2001;5:42-8.

13. Koelz HR. Contra Chirurgie bei gastroösophagealer Refluxkrankheit. Chir Gastroenterol 1997;13:147-57.

14. Bammer T, Hinder RA, Klaus A, Trastek VF, Achem SR. Rationale for surgical therapy of Barrett esophagus. Mayo Clin Proc 2001;76:335-42.

15. Sonnenberg A, El-Serag HB. Clinical epidemiology and natural history of gastroesophageal reflux disease. Yale J Biol Med 1999;72:81-92.

16. Fein M, Peters JH, Chandrasoma P, et al. Duodenoesophageal reflux induces esophageal adenocarcinoma without exogenous carcinogen. J Gastrointest Surg 1998;2:260-8.

17. El-Serag HB, Sonnenberg A. Opposing time trends of peptic ulcer and reflux disease. Gut 1998;43:327-33.

18. El-Serag HB, Sonnenberg A, Jamal MM, Inadomi JM, Crooks LA, Feddersen RM. Corpus gastritis is protective against reflux oesophagitis. Gut 1999;45:181-5.

19. Soni A, Sampliner RE, Sonnenberg A. Screening for high-grade dysplasia in gastroesophageal reflux disease: is it cost-effective? Am J Gastroenterol 2000;95:2086-93.

20. Wachterhauser BR, ed. Hermeneutics and Truth. Evanston: Northwestern University Press, 1994.

21. Kuhn TS. The Structure of Scientific Revolutions, 2nd edn. Chicago: University of Chicago Press, 1970. 


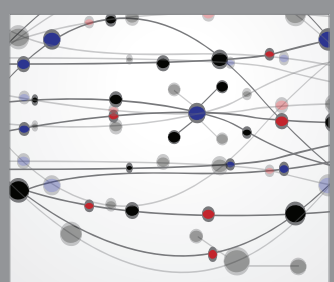

The Scientific World Journal
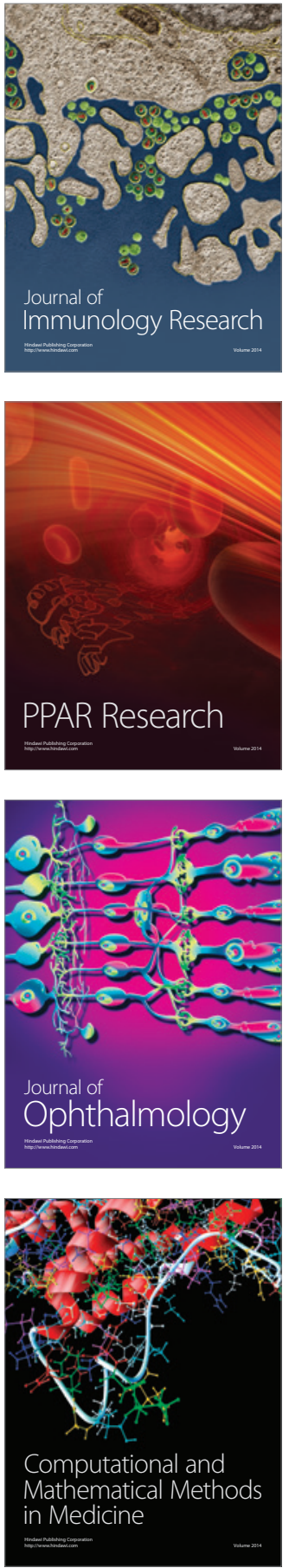

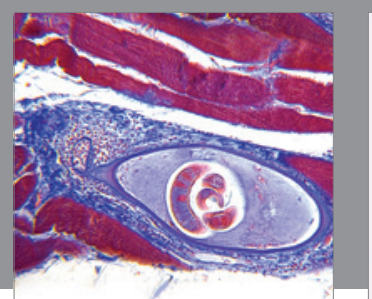

Gastroenterology Research and Practice

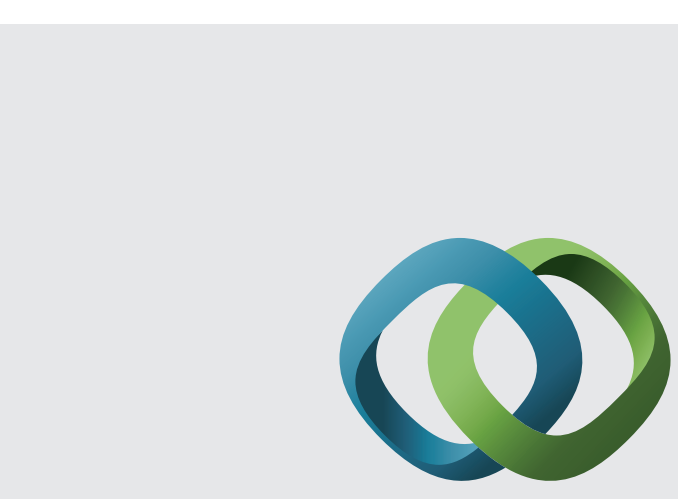

\section{Hindawi}

Submit your manuscripts at

http://www.hindawi.com
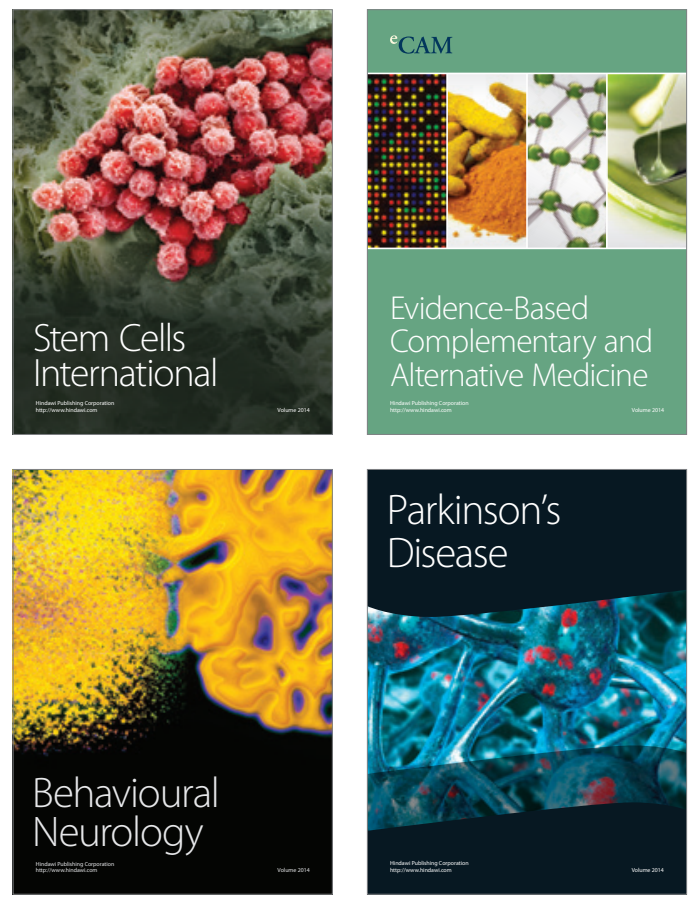
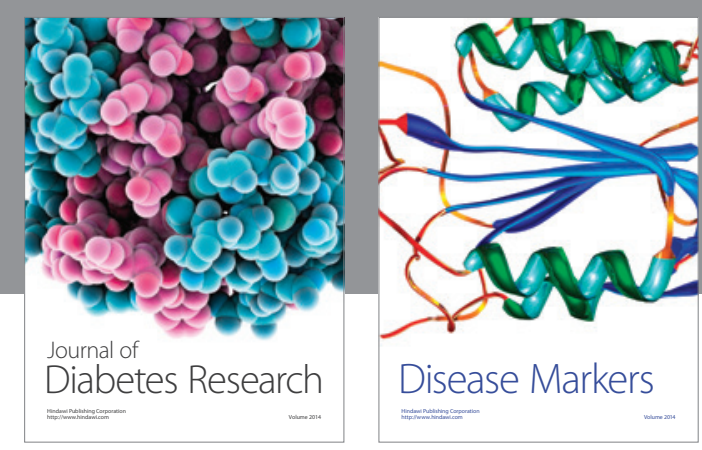

Disease Markers
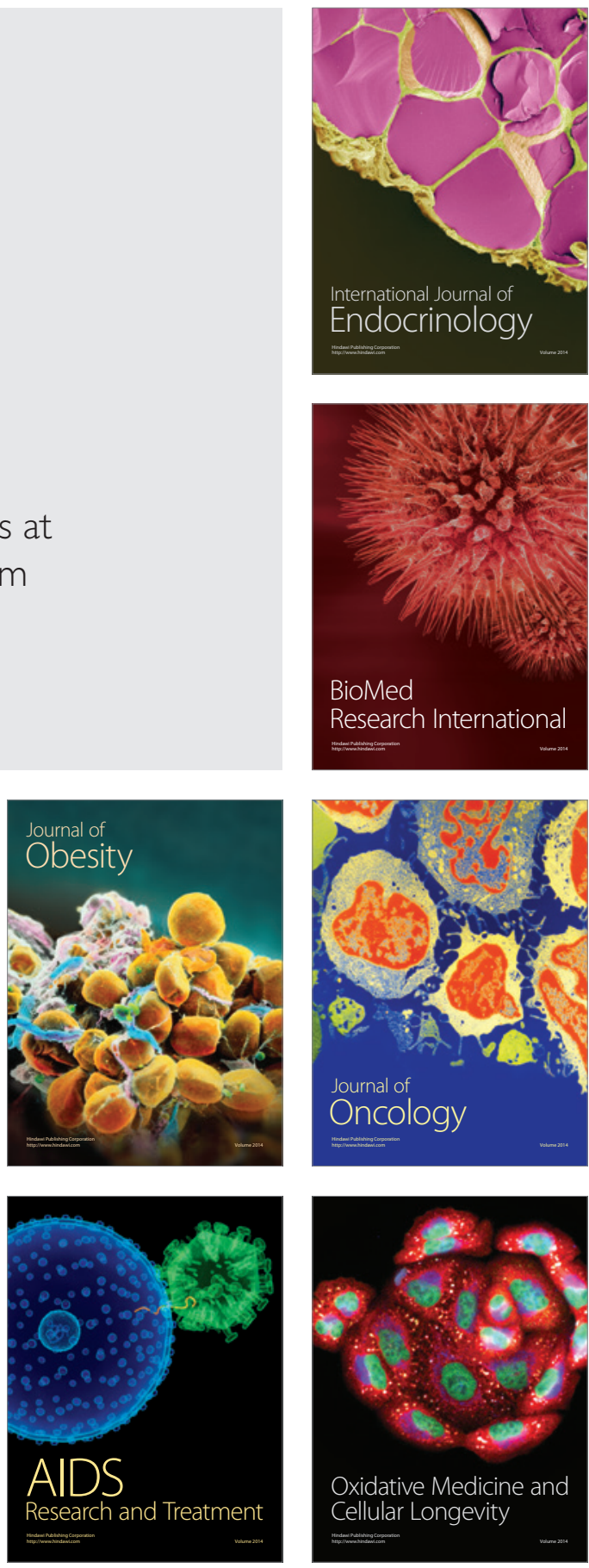